Review Article

\title{
Genomic Approach to Understand the Association of DNA Repair with Longevity and Healthy Aging Using Genomic Databases of Oldest-Old Population
}

\author{
Yeo Jin Kim $\mathbb{D}^{1,2}$ Hyun Soo Kim, ${ }^{1,2}$ and Young Rok Seo $\mathbb{D}^{1,2,3}$ \\ ${ }^{1}$ Department of Life Science, Dongguk University Biomedi Campus, 32 Dongguk-ro, Ilsandong-gu, Goyang-si, \\ Gyeonggi-do 10326, Republic of Korea \\ ${ }^{2}$ Institute of Environmental Medicine, Dongguk University Biomedi Campus, 32 Dongguk-ro, Ilsandong-gu, Goyang-si, \\ Gyeonggi-do 10326, Republic of Korea \\ ${ }^{3}$ The Jackson Laboratory for Genomic Medicine, 10 Discovery Drive, Farmington, CT 06032, USA
}

Correspondence should be addressed to Young Rok Seo; seoyr@dongguk.edu

Received 27 January 2018; Accepted 3 April 2018; Published 3 May 2018

Academic Editor: Sharbel W. Maluf

Copyright (C) 2018 Yeo Jin Kim et al. This is an open access article distributed under the Creative Commons Attribution License, which permits unrestricted use, distribution, and reproduction in any medium, provided the original work is properly cited.

\begin{abstract}
Aged population is increasing worldwide due to the aging process that is inevitable. Accordingly, longevity and healthy aging have been spotlighted to promote social contribution of aged population. Many studies in the past few decades have reported the process of aging and longevity, emphasizing the importance of maintaining genomic stability in exceptionally long-lived population. Underlying reason of longevity remains unclear due to its complexity involving multiple factors. With advances in sequencing technology and human genome-associated approaches, studies based on population-based genomic studies are increasing. In this review, we summarize recent longevity and healthy aging studies of human population focusing on DNA repair as a major factor in maintaining genome integrity. To keep pace with recent growth in genomic research, aging- and longevity-associated genomic databases are also briefly introduced. To suggest novel approaches to investigate longevity-associated genetic variants related to DNA repair using genomic databases, gene set analysis was conducted, focusing on DNA repair- and longevity-associated genes. Their biological networks were additionally analyzed to grasp major factors containing genetic variants of human longevity and healthy aging in DNA repair mechanisms. In summary, this review emphasizes DNA repair activity in human longevity and suggests approach to conduct DNA repair-associated genomic study on human healthy aging.
\end{abstract}

\section{Introduction}

Aging is an inevitable process in human life. Many countries are rapidly transitioning to an aging society due to increasing life expectancy and advanced medical supports [1-3]. Over the last few decades, the advent of aging society is considered a crucial issue that may cause future decline in productivity of community $[1,4]$. Many researchers have recently warned that urban environmental pollutants can cause physiological weakness and increase the risk of premature aging or chronic diseases in the elderly population [5-9]. Thus, interest in antiaging and healthy longevity is constantly increasing. "Active aging" or "successful aging" has been spotlighted as a strategy to promote social contribution of the elderly [10]. The definition of successful aging remains controversial. However, its main point is to live a healthy life in physical, cognitive, and biomedical aspects [10-12]. Although many studies have dealt with the topic of aging in the past, it is too complex to clearly understand fundamental causes of the aging process.

Longevity is usually defined as living until life expectancy that is typically over 85 years old. Exceptional longevity such as centenarians is considered when one is more than 95 years old with a healthy life $[10,13]$. Several researchers have emphasized the importance of in-depth studies on longevity to cope with an aging society $[14,15]$ because such studies 
could suggest various biomedical clues for living a long and healthy life. Oldest-old individuals, often centenarians, represent an adequate model to investigate the complex phenotype of healthy longevity. Among enormous populationbased studies on centenarians, one major focus is on people with exceptionally long lives without functional impairment $[10,16-21]$. Several landmark studies on healthy centenarians have found that the progression of major diseases such as cancer, cardiovascular disease, and stroke is delayed in the oldest group compared to that in the other younger or same-aged control groups, suggesting a substantial relationship between healthspan and longevity [10, 20, 22].

Although successful longevity traits are modulated by various factors, such as environmental, behavioral, and/or endogenous causes, genetic factor might be a major factor that contributes to healthy aging. Within the past few decades, many researchers have tried to identify longevityassociated genes using diverse species, ranging from less complex organisms to higher organisms $[18,23-26]$. With development in genomic technology, genetic factors associated with longevity have been suggested in human population studies and human genome-wide association studies $[18,21,27]$. It has been found that variants of APOE and FOXO3A are highly associated with longevity. This finding has been consistently replicated in many different population-based studies [21,28-30]. Despite the complexity of healthy longevity in human due to various influences, genetic factors are thought to be exceedingly important to understand the genetic basis of longevity. Accordingly, many studies have investigated various genetic factors, including nuclear genomic variants, mitochondrial variants, telomere, and epigenetics, to elucidate the substantial contribution of genetic factors to longevity [31-34].

Accumulation of DNA damage is associated with functional decline in the aging process [35-37]. Thus, maintenance of genomic integrity might be a crucial factor for healthy life and longevity. Genome instability generally increases with age. DNA repair machineries control genome stability [38]. Previous studies on centenarian have shown that oldest-old population have enhanced DNA repair activity with significant lower frequency in genomic and cellular damage compared to their younger counterparts $[35,39,40]$. Thus, DNA repair plays an important role in understanding exceptionally long-lived individuals.

In this review, we focus on major DNA repair machineries associated with longevity. We also explored longevityassociated population studies using genome-wide approaches. With brief introductions of genomic databases in aging and longevity field, ample genomic resources of normal long-lived human population were utilized for DNA repair-focused approach. Herein, we suggest a new aspect of longevity study to investigate the complex interplay between DNA repair and longevity by processing human genetic variations based on previous studies, providing a brief interpretation of their molecular networks. This review not only provides an overview of the importance of DNA repair mechanism in longevity but also suggests a novel approach to select candidate genes associated with healthy aging in human.

\section{Healthy Traits of Long-Lived Population}

As concerns about longevity increase, many research studies have investigated longevity using model organisms to understand the association between genetic contribution and lifespan $[23,24,26,41-43]$. However, human lifespan is too complex to clearly elucidate its biological and sociocultural factors. Therefore, many studies on human longevity have been conducted epidemiologically by comparing populations divided by age [44-47]. Recently, older population with good health and longevity has been investigated to characterize healthy aging phenotypes and differences compared to those with same age or younger to provide better public health care [48-51]. Nolen et al. have published a comprehensive review on cancer prevalence in the oldest-old population and found that centenarians and the oldest-old have lower risk of cancer [50]. In Japan, where there is a relatively high population of centenarians, the Okinawa Centenarian Study, the world's longest-running population-based study of centenarians, has been performed to understand the contribution of genetic and environmental factors to exceptional longevity [18]. Interestingly, these studies commonly concluded that not all elder people showed higher degree of age-associated disorders. In fact, long-lived individuals with inherited predisposition and their offspring showed beneficial profiles of major disabilities [18, 48-50, 52, 53]. However, understanding about the effect of genetic factors on longevity is still limited. Novel gene and/or genetic variations and contribution of different aspects to longevity need to be determined in the future.

Enhanced DNA repair capacity is thought to be a crucial factor for healthy longevity based on previous studies using oldest-old population $[40,54]$. Evidence for improved DNA repair system that leads to delayed aging has been accumulated based on several human population studies [55-57]. Indeed, the frequency of DNA damages such as cytogenic aberrations and micronuclei is significantly lower in the oldest age group than that in the other groups, suggesting more genomic stability in the oldest-old population [58]. However, Chevanne et al. [40] have reported that DNA repair capacity in centenarians is similar to that in young generations. In accordance to these findings, the importance of DNA repair activity in longevity needs to be clarified to elucidate factors associated with longevity.

\section{DNA Repair and Longevity}

Disturbance of genome integrity is commonly known as a staple factor in the etiology of age-related cellular dysfunction and pathogenesis, although a plethora of extrinsic and intrinsic factors can also threaten genome stability. Accumulated DNA damage can lead to cellular dysfunction, cell death, and carcinogenesis. Generally, DNA repair mechanisms in cellular protection system can rescue various cytotoxic and mutagenic lesions to maintain DNA integrity. Accordingly, studies on the association between DNA repair mechanism and aging are increasing. In this review, we only focused on DNA double-strand break repair, base excision repair (BER), and nucleotide excision repair (NER) 
associated with aging and longevity in terms of maintaining genome integrity. Although there are many kinds of DNA repair mechanisms to prevent genomic instability, other pathways have been more related to diseases such as cancer and disorders other than aging [59-62].

Age-related increase of DNA double-strand breaks is consistently considered as a genetic blueprint of progeroid syndromes because DNA double-strand breaks cause the most deleterious damage to DNA [63-65]. Major repair pathways for DNA double-strand breaks are homologous recombination (HR) and nonhomologous end joining (NHEJ). HR uses undamaged sister chromatid as template during cell division. It is an error-free pathway [66]. NHEJ occurs even in G1 phase of the cell cycle where sister chromatid does not exist. It can join the ends of a double-stand break without a template [67]. Several studies have shown that DNA double-strand break repair is reduced in the aging population $[63,68,69]$. Many proteins involved in the NHEJ process need to maintain telomeres. Ku70, Ku80, DNA$\mathrm{PK}_{\mathrm{CS}}, \mathrm{WRN}$, and PARP1 are key proteins of genome integrity [70-73]. Deficiency of these proteins induces premature aging and age-associated disorders [74-76]. Recently, it has been found that SIRT6, one longevity gene, is involved in DNA double-strand break repair by recruiting PARP1 to damaged DNA region [77].

One major hypothesis on aging is that exposure to reactive oxygen species (ROS) is increased over the lifespan [63, $69,78]$. The production of ROS can be induced by multiple extrinsic and intrinsic factors. It causes various kinds of DNA damage, including apurinic/apyrimidinic sites due to DNA base lose, single-strand break, and double-strand break $[79,80]$. Accumulated DNA damages due to ROS frequently lead to cellular dysfunction, a known consequence of chronic oxidative stress with aging [78]. Several defense mechanisms, including DNA repair machinery, can cope with the threat of ROS [81]. BER predominantly corrects oxidative lesions [82]. Indeed, many subunits such as APE1, PCNA, and HSP70 related to BER pathway are involved in the defense mechanism against cellular oxidative stress, including DNA repair [82]. Many studies have shown the association between BER and aging. For example, BER capacity is significantly decreased in brain and liver tissues of old mice [83]. Many studies have also reported that the decline of major components ( $\operatorname{pol} \beta$, pol $\gamma, \mathrm{APE} 1$, and Sirt6) of BER pathway is associated with aging [84-89]. Interestingly, deficiency of APE1, a vital element of BER initiation, leads to telomere dysfunction and segregation, suggesting that BER plays a role in aging through telomere protection $[90,91]$.

NER, another type of DNA repair pathway, copes with a wide range of lesions that distort the double helix structure of DNA [81]. DNA bulky damages recognized by NER can cause premature aging and/or cancer $[92,93]$. NER is subdivided into global genome NER and transcription-coupled NER depending on where it occurs, covering lesions that can be detected by NER subunits $[60,94]$. Some NER proteins are thought to be important factors in the aging process due to their direct association with progeroid syndromes such as trichothiodystrophy (TTD), Cockayne syndrome (CS), and xeroderma pigmentosum (XP) [95-98]. A point mutation at different sites in XPD gene can trigger TTD or CS [96]. A defect in XP gene family (XPA-XPG) induces $\mathrm{XP}$. The patient with such defect has shown dramatically accelerated skin aging [99]. Although whether decline of NER efficiency is associated with aging remains controversial [100-102], defect in NER machinery virtually provokes agerelated pathology and premature aging. Hermetic effects on this aspect supports the crucial role of NER in healthy aging through conserved pathway [103-105]. A prominent mechanism of cellular protective responses is regulation of IGF-1 signaling that leads to somatotropic attenuation by RNA polymerase II stalling. Interestingly, this prosurvival response was commonly found in naturally aged, progeroid, and long-lived mutant mice [106-108]. However, the mechanism eventually enhances longevity assurance in wild type, while it has severe consequences in NER defects [104, 105]. In this regard, the modulation of DNA damage is thought to be a more significant factor with a prosurvival harbor [107]. Other intrinsic or extrinsic factors, of course, should have to be considered for elucidating this complicated process. Thus, understanding longevity in terms of DNA repair is crucial in the aspect of genome integrity preservation. The complex interplay between DNA repair and longevity remains unclear.

\section{Genomic Resources for Understanding Aging and Longevity}

Although longevity is a multifactorial process, genomic approaches can be used to elucidate biological aspects of longevity by identifying standardized parameters such as biomarkers [109]. With development of next-generation sequencing, a large number of long-lived individuals have been studied to obtain their specific genomic information such as single nucleotide polymorphisms, copy number variations, transcriptomics, and epigenomics [110-114]. Although disease-susceptibility alleles are well characterized in genome-wide association study (GWAS) catalog by the National Human Genome Research Institute, research data for illustrating low frequency of disease alleles in exceptional longevity are limited or controversial [115]. Up to date, APOE and FOXO3A have been consistently suggested as well-described candidate genes in human longevity by various cross-sectional studies [21, 116, 117]. Furthermore, joint roles of genetic variants and phenotypes in longevity have been suggested to improve our understanding on aging and longevity [48]. Pathway-based candidate gene studies have been performed to encompass their molecular and biological networks in longevity [118-121]. However, their roles in longevity remain controversial.

Based on exponentially accumulated data, major aging research groups have started global interdisciplinary collaboration to share large scale genomic resources obtained from sequencing data [122]. Human Ageing Genomic Resources (HAGR; http://genomics.senescence.info) provides in-depth information about the biology and genetics of aging [123]. HAGR now includes six core databases: GenAge, AnAge, GenDR, DrugAge, and LongevityMap. GenAge contains benchmark database of genes associated with aging. It is 
TABLE 1: Summary of DNA repair-associated genes with significant genomic variants in longevity.

\begin{tabular}{|c|c|c|c|c|}
\hline Genes & Variations & Region & Populations & References \\
\hline \multirow{2}{*}{ ATM } & \multirow{2}{*}{ rs 189037} & \multirow{2}{*}{$5^{\prime}$-UTR } & Chinese (Han) & {$[132]$} \\
\hline & & & Italian & {$[133]$} \\
\hline ATRIP & rs9876781 & Upstream & American (Caucasian) & {$[134]$} \\
\hline \multirow{4}{*}{ EGFR } & rs2072454 & Exon (synonymous) & \multirow{4}{*}{ Korean } & \multirow{4}{*}[135]{} \\
\hline & rs2293347 & Exon (synonymous) & & \\
\hline & rs 3807362 & $3^{\prime}$-UTR & & \\
\hline & rs884225 & $3^{\prime}$-UTR & & \\
\hline ERCC2 & Lys751Gln ${ }^{\S}$ & Missense (stop-gain) & Polish & {$[136]$} \\
\hline \multirow{3}{*}{ EXO1 } & rs1776180 & Upstream & \multirow{3}{*}{ German } & \multirow{3}{*}[137]{} \\
\hline & rs735943 & Exon (missense; H/R) & & \\
\hline & rs4149965 & Exon (missense; V/M or V/L) & & \\
\hline \multirow{3}{*}{ HSPA1A } & \multirow{2}{*}{$-110 \mathrm{~A} / \mathrm{C}$} & \multirow{2}{*}{ Upstream $^{\S \S}$} & Italian (Southern) & [138] \\
\hline & & & Danish & [139-141] \\
\hline & G190C & $\$ s$ & Chinese (Uighur in Xinjiang) & {$[142]$} \\
\hline \multirow{2}{*}{ HSPA1B } & \multirow{2}{*}{ A1267G } & \multirow{2}{*}{$\$ s$} & Danish & {$[141]$} \\
\hline & & & Chinese (Uighur in Xinjiang) & {$[142]$} \\
\hline \multirow{2}{*}{ HSPA1L } & \multirow{2}{*}{ T2437C } & \multirow{2}{*}{ ss } & Danish & {$[141]$} \\
\hline & & & Chinese (Uighur in Xinjiang) & {$[142]$} \\
\hline \multirow{2}{*}{ MLH1 } & C670, A676, T1172 & $\$ \$$ & Korean & {$[143]$} \\
\hline & rs13320360 & Intron & Danish & {$[119]$} \\
\hline POLB & rs2953983 & Intron & Danish & [119] \\
\hline RAD23B & rs1805329 & Exon (missense; A/V) & Danish & [119] \\
\hline RAD52 & rs11571461 & Intron & Danish & {$[119]$} \\
\hline \multirow{4}{*}{ SIRT1 } & rs3758391 & Upstream & \multirow{2}{*}{ Chinese (Han) } & \multirow{2}{*}[144]{} \\
\hline & rs4746720 & $3^{\prime}$-UTR & & \\
\hline & rs7896005 & Intron & American (Caucasian) & {$[145]$} \\
\hline & rs 12778366 & Upstream & Dutch & {$[146]$} \\
\hline \multirow{3}{*}{ TP53 } & \multirow{2}{*}{ rs1042522 } & \multirow{2}{*}{ Exon (missense; $\mathrm{P} / \mathrm{R}$ or $\mathrm{P} / \mathrm{H}$ ) } & Danish & {$[127]$} \\
\hline & & & Italian (Central) & {$[128]$} \\
\hline & rs9616906 & Upstream & American (Caucasian) & {$[134]$} \\
\hline WRN & rs13251813 & Intron & Danish & [119] \\
\hline XRCC5 & rs705649 & Intron & Danish & [119] \\
\hline
\end{tabular}

${ }^{\S}$ Variation in amino acid; ${ }^{\S \S}$ studies on haplotype analysis.

now subdivided into two: (1) potential aging-related genes in human and (2) lifespan-associated genes in model organisms [124]. AnAge is a database of aging and longevity in animals for comparative and evolutionary studies in this field [124]. Since there are many theories and factors of aging and longevity, HAGR has been expanded. It now has new categories to deal with different aspects of this issue. GenDR is focused on dietary restriction. DrugAge is a database of life-extending drugs in model organisms. CellAge is a very recent database to support overall cellular longevity study [125]. LongevityMap is an inclusive database based on genomic studies of human longevity and healthy aging, excluding long-lived individuals who have unhealthy traits such as disease, disorder, and/or dysfunction [126]. Utilizing these open source data may aid biogerontologists to interpret human aging and longevity in diverse aspects of the complex process involved in aging and longevity.

\section{DNA Repair and Longevity-Associated Genetic Variation}

With valuable longevity population data in longevity databases, we investigated healthy longevity-associated genetic variations in terms of major elements of DNA repair mechanism. We focused on people with normal phenotype in elder population. Data of human genetic variants associated with longevity were retrieved from LongevityMap. Contents of enormous studies on human longevity and healthy aging ranging from cross-sectional investigations to extreme longevity are curated in LongevityMap [126]. 


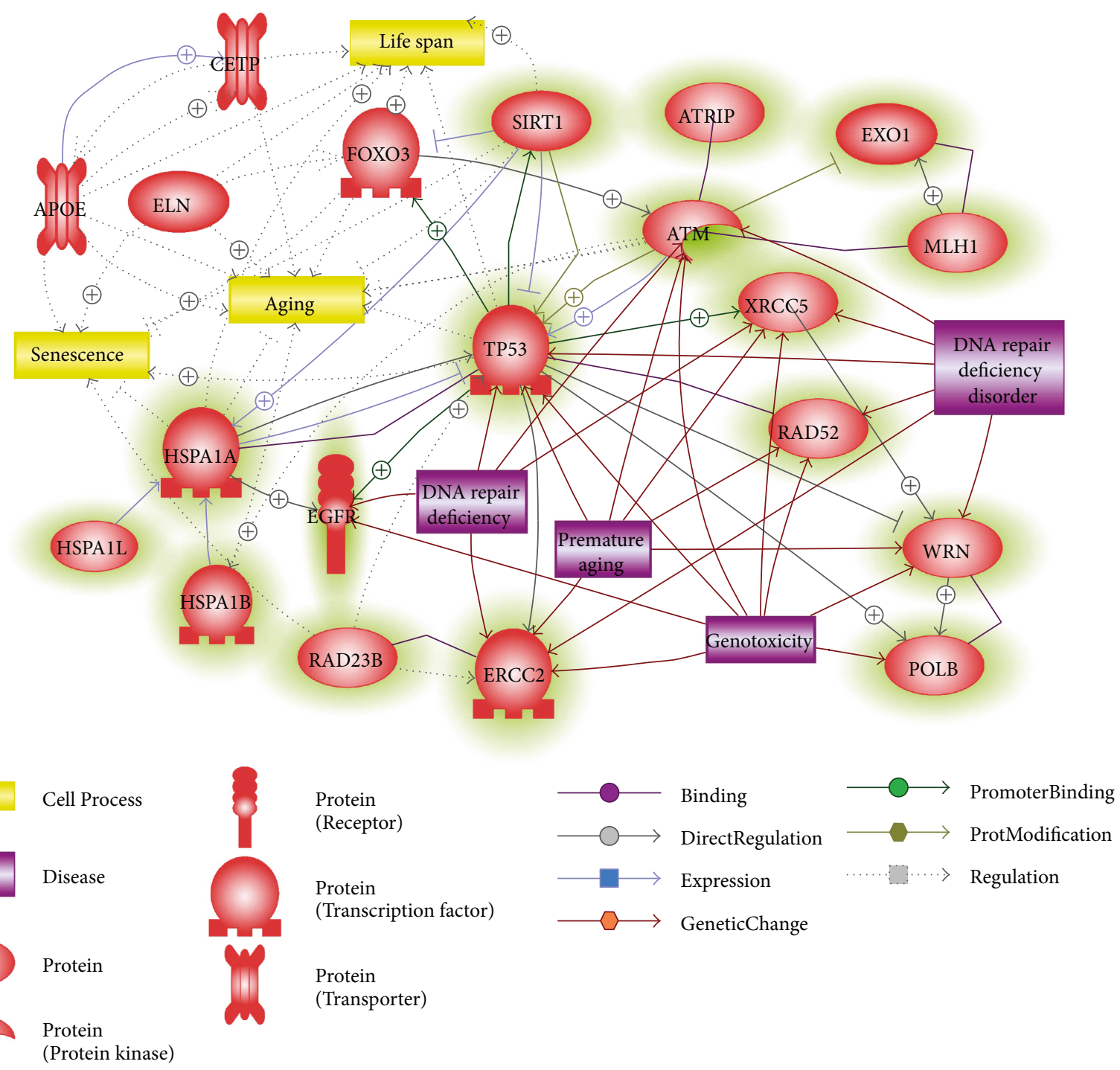

Figure 1: Direct networks among genes obtained by comparison of gene sets associated with DNA repair and human longevity. The analysis of molecular and biological networks was conducted by using Pathway Studio Web (version 11.4.0.8). Green highlighted entities indicate 16 common genes obtained by gene set comparison. These networks were built with careful curation considering the number of reference ( $>10)$ and their correlation with longevity, aging, and DNA repair.

We trimmed these data by their significance in association with longevity. To elucidate correlations between human healthy longevity and DNA repair in the aspect of genetic variants, we collected genes associated with canonical DNA repair mechanisms from well-reviewed publications. DNA repairassociated genes were obtained through search using keywords such as NER, BER, NHEJ, HR, and MMR in human-oriented samples. Gene sets that had significant association with longevity and DNA repair were analyzed to identify common genes in these two groups. As a result, 16 genes were obtained, including key factors of DNA repair mechanism such as TP53, ATM, WRN, and POLB (Table 1). These results should be cautiously grasped. For instance, in case of rs1042522 on TP53 gene, two different population studies suggested opposite interpretations on the same SNP [127, 128]. However, the two studies also described common cellular effects of each allele as well. This may be due to differentially designed population studies (cross-sectional versus prospective followup). Their advantages and pitfalls in each methodological strategy must be considered seriously to understand population studies, especially, for aging and longevity, because these are very complex and multifactorial processes. Therefore, complicated interactions instead of a single factor should be taken into account. In addition, integrative approach should be used to understand aging and longevity.

\section{Complex Interplay on DNA Repair Mechanism}

To interpret the meaning of these common genes, biological network analysis was conducted using Pathway Studio, a text mining-based pathway analysis program. Recently, analyzing molecular network is considered a more critical part than just detecting alteration of DNA sequence and/or gene expression 
Persisted DNA repair triggers tenomic instability EXO1;RAD52;ATM;H2AFX;WRN;XRCC5;POLB

Telomer attrition triggers genomic instability ATM;WRN;XRCC5;TP53

Replication stress triggers genomic instability ATM;ATRIP;ERCC2;H2AFX

SIRT 1 signaling in aging SIRT1;HSPA1A;TP53

DNA persistent repair inhibits mTOR signaling SIRT1;ATM;TP53

SIRT 6 signaling in aging TP53;WRN;POLB

Oncogene-induced cellular senescence ATM;TP53

Macroautophagy decline SIRT1;TP53

mTOR signaling overview TP53

Hypoxia inhibits mTOR signaling SIRT1

1

2

4

5

6

8

(a)

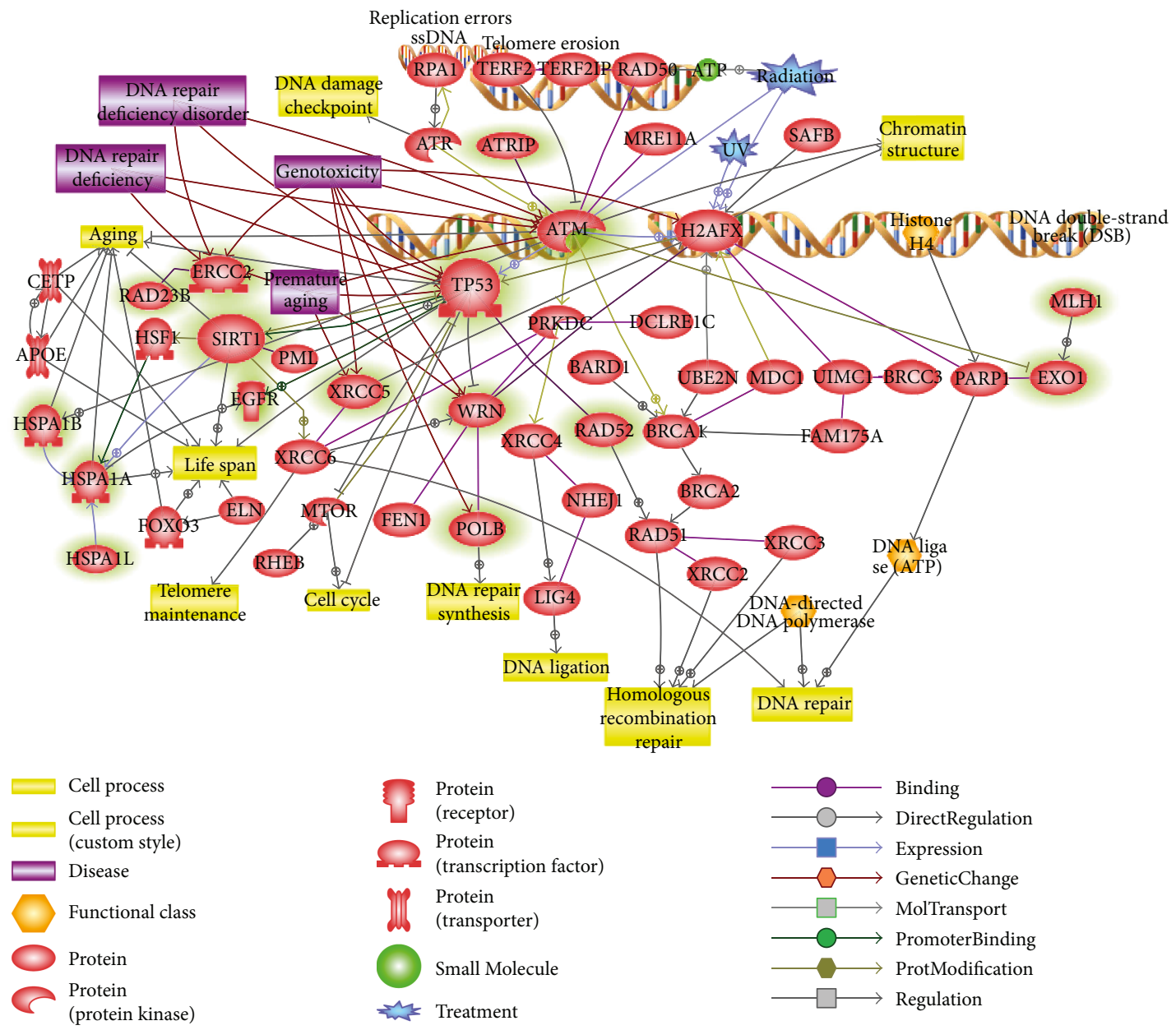

(b)

FIGURE 2: Major enriched networks of common genes and the top ranked pathway suggesting key contributors to longevity in aspect of DNA repair. (a) Pathways and ontologies enriched in these genes shown in a bar graph. $x$-axis indicates the number of overlapped genes with elements of each pathway/ontology while $y$-axis shows the name of statistically meaningful pathways/ontologies $(p$ value $<0.05)$. (b) The most enriched pathway, "persisted DNA repair triggers genomic instability," and direct pathway analyzed previously were combined using Pathway Studio Web (version 11.4.0.8) to explore major genes including candidate longevity-associated loci in DNA repair to provide better visualization. Green highlighted entities indicate common genes collected by gene set comparison. 
to understand difference in phenotype. Various tools have been developed to conduct network analysis for genes of interest due to advance in bioinformatics industry and accumulating research products. Pathway Studio as a commercial software for biological pathway analysis can navigate related biological processes using data mining interface [129]. In this review, we explored interacting networks of these $16 \mathrm{com}$ mon genes to elucidate the role of DNA repair in longevity using Pathway Studio. These genes were initially analyzed for their direct interactions and correlations with lifespanassociated genes and cell processes (Figure 1). Many of these genes are known as genetic parameters of genomic instability and premature aging. According to results of our network analysis, TP53, ATM, and SIRT1 were the top three elements with high number of connections with others, suggesting that their genetic variants might be considered as key nodes to elucidate genetic contribution of major DNA repair factors to longevity and healthy aging.

We also conducted gene set enrichment analysis using the Pathway Studio software to explore which pathways and ontologies might be mostly involved in these common genes associated with DNA repair and longevity. Statistical enrichment in this gene set was collected. We curated the result by a $p$ value of less than 0.05 (Figure 2(a)). Approximately half of these 16 common genes had overlapped biological function, namely, "persisted DNA repair triggers genomic instability." For better visualization, pathways of biological function derived from this software and those of direct network from our analysis were combined (Figure 2(b)). The results showed that ATM and TP53 played a major role in DNA repair by detecting DNA damage and modulating downstream DNA repair machineries. Although further meticulous study is needed to confirm their roles in longevity, longevity-associated human genetic variants in TP53, ATM, and SIRT1 are worth considering to identify potential key factors and understand the linkage of DNA repair to longevity and healthy aging.

\section{Conclusions}

Although the importance of genomic stability in longevity is continuously discussed $[35,130,131]$, studies using genomic and molecular approaches to understand genetic variations of extremely old population in the aspect of DNA repair are limited. In this review, we focused on DNA repair mechanisms associated with longevity and healthy aging to elucidate their effects on the aging process. As reported in many studies, this review also emphasized the role of DNA repair in maintaining genome integrity as a crucial factor for healthy longevity. With enormous resources of human longevity population that are freely available online based on NGS studies, DNA repair-focused approach is useful for identifying the association of genes with longevity by integrated network analysis. This research approach could be ideal and valuable for handling genomic data. The present review may provide a clue to utilize genomic databases to elucidate contribution of genetic factors to longevity in many different aspects. Although we only dealt with DNA repair associated with longevity, comprehensive data from lifestyles should be considered to better understand the process of healthy aging. It might lead to the development of personalized antiaging strategy.

\section{Conflicts of Interest}

The authors declare that there is no conflict of interest regarding the publication of this article.

\section{Acknowledgments}

The authors would like to show their gratitude to Dong Wook Shin, Ph.D., Hyoung-June Kim, Ph.D., Moo Kyun Park, Ph.D., and Charles Lee, Ph.D., for their comments that greatly improved this manuscript. This work was supported partially by a grant from the Amorepacific Corporation $\mathrm{R} \& \mathrm{D}$ Center and by another grant (Grant no. 2016001360009) from the Environmental Health Action Program funded by the Ministry of Environment (MOE), Republic of Korea. Also, this work was funded in part by a grant from The Jackson Laboratory to Charles Lee.

\section{References}

[1] J. M. Wiener and J. Tilly, "Population ageing in the United States of America: implications for public programmes," International Journal of Epidemiology, vol. 31, no. 4, pp. 776-781, 2002.

[2] W. C. Sanderson and S. Scherbov, "Measuring the speed of aging across population subgroups," PLoS One, vol. 9, no. 5, article e96289, 2014.

[3] B. Contoli, P. Carrieri, M. Masocco, L. Penna, A. Perra, and PDA Study Group, "PASSI d'Argento (Silver Steps): the main features of the new nationwide surveillance system for the ageing Italian population, Italy 2013-2014," Annali dell'Istituto Superiore di Sanità, vol. 52, no. 4, pp. 536-542, 2016.

[4] T. Bengtsson and K. Scott, "Population aging and the future of the welfare state: the example of Sweden," Population and Development Review, vol. 37, Supplement 1, pp. 158170, 2011.

[5] Y. H. Choi, J. H. Kim, and Y. C. Hong, "Sex-dependent and body weight-dependent associations between environmental PAHs exposure and insulin resistance: Korean urban elderly panel," Journal of Epidemiology \& Community Health, vol. 69, no. 7, pp. 625-631, 2015.

[6] X. Zhang, S. Lin, W. E. Funk, and L. Hou, "Environmental and occupational exposure to chemicals and telomere length in human studies," Occupational \& Environmental Medicine, vol. 70, no. 10, pp. 743-749, 2013.

[7] K. L. Shumake, J. D. Sacks, J. S. Lee, and D. O. Johns, "Susceptibility of older adults to health effects induced by ambient air pollutants regulated by the European Union and the United States," Aging Clinical and Experimental Research, vol. 25, no. 1, pp. 3-8, 2013.

[8] D. Black, K. O'Loughlin, H. Kendig, and L. Wilson, "Cities, environmental stressors, ageing and chronic disease," Australasian Journal on Ageing, vol. 31, no. 3, pp. 147151, 2012.

[9] J. F. Risher, G. D. Todd, D. Meyer, and C. L. Zunker, "The elderly as a sensitive population in environmental exposures: 
making the case," Reviews of Environmental Contamination and Toxicology, vol. 207, pp. 95-157, 2010.

[10] P. Martin, N. Kelly, B. Kahana et al., "Defining successful aging: a tangible or elusive concept?," The Gerontologist, vol. 55, no. 1, pp. 14-25, 2015.

[11] E. A. Phelan, L. A. Anderson, A. Z. LaCroix, and E. B. Larson, "Older adults" views of "successful aging"- how do they compare with researchers' definitions?," Journal of the American Geriatrics Society, vol. 52, no. 2, pp. 211-216, 2004.

[12] L. F. Carver and D. Buchanan, "Successful aging: considering non-biomedical constructs," Clinical Interventions in Aging, vol. 11, pp. 1623-1630, 2016.

[13] S. N. Rajpathak, Y. Liu, O. Ben-David et al., "Lifestyle factors of people with exceptional longevity," Journal of the American Geriatrics Society, vol. 59, no. 8, pp. 15091512, 2011.

[14] R. Alzetta, A. Cesario, and M. Fini, "Hyper-longevity, a latemodern paradigm for understanding longevity, ageing and their complexities in Western developed globalised countries," Current Pharmaceutical Design, vol. 20, no. 38, pp. 5921-5927, 2014.

[15] M. Noale, F. Limongi, E. Scafato, S. Maggi, and G. Crepaldi, "Longevity and health expectancy in an ageing society: implications for public health in Italy," Annali dell'Istituto Superiore di Sanità, vol. 48, no. 3, pp. 292-299, 2012.

[16] J. Arnold, J. Dai, L. Nahapetyan et al., "Predicting successful aging in a population-based sample of Georgia centenarians," Current Gerontology and Geriatrics Research, vol. 2010, Article ID 989315, 9 pages, 2010.

[17] J. Cho, P. Martin, and L. W. Poon, "The older they are, the less successful they become? findings from the Georgia Centenarian Study," Journal of Aging Research, vol. 2012, Article ID 695854, 8 pages, 2012.

[18] D. C. Willcox, B. J. Willcox, W. C. Hsueh, and M. Suzuki, "Genetic determinants of exceptional human longevity: insights from the Okinawa Centenarian Study," Age, vol. 28, no. 4, pp. 313-332, 2006.

[19] A. Toyoshima, P. Martin, S. Sato, and L. W. Poon, "The relationship between vision impairment and well-being among centenarians: findings from the Georgia Centenarian Study," International Journal of Geriatric Psychiatry, vol. 33, no. 2, pp. 414-422, 2018.

[20] S. L. Andersen, P. Sebastiani, D. A. Dworkis, L. Feldman, and T. T. Perls, "Health span approximates life span among many supercentenarians: compression of morbidity at the approximate limit of life span," The Journals of Gerontology Series A: Biological Sciences and Medical Sciences, vol. 67A, no. 4, pp. 395-405, 2012.

[21] A. R. Brooks-Wilson, "Genetics of healthy aging and longevity," Human Genetics, vol. 132, no. 12, pp. 1323-1338, 2013.

[22] J. F. Fries, "Aging, natural death, and the compression of morbidity," The New England Journal of Medicine, vol. 303, no. 3, pp. 130-135, 1980.

[23] M. Beekman, G. J. Blauw, J. J. Houwing-Duistermaat, B. W. Brandt, R. G. J. Westendorp, and P. E. Slagboom, "Chromosome 4q25, microsomal transfer protein gene, and human longevity: novel data and a meta-analysis of association studies," The Journals of Gerontology Series A: Biological Sciences and Medical Sciences, vol. 61, no. 4, pp. 355-362, 2006.
[24] M. Barbieri, M. Bonafe, C. Franceschi, and G. Paolisso, "Insulin/IGF-I-signaling pathway: an evolutionarily conserved mechanism of longevity from yeast to humans," American Journal of Physiology-Endocrinology and Metabolism, vol. 285, no. 5, pp. E1064-E1071, 2003.

[25] Y. J. Lin, L. Seroude, and S. Benzer, "Extended life-span and stress resistance in the Drosophila mutant Methuselah," Science, vol. 282, no. 5390, pp. 943-946, 1998.

[26] H. R. Warner, "Longevity genes: from primitive organisms to humans," Mechanisms of Ageing and Development, vol. 126, no. 2, pp. 235-242, 2005.

[27] A. B. Newman and J. M. Murabito, "The epidemiology of longevity and exceptional survival," Epidemiologic Reviews, vol. 35, no. 1, pp. 181-197, 2013.

[28] F. Flachsbart, A. Caliebe, R. Kleindorp et al., "Association of FOXO3A variation with human longevity confirmed in German centenarians," Proceedings of the National Academy of Sciences of the United States of America, vol. 106, no. 8, pp. 2700-2705, 2009.

[29] R. Jacobsen, T. Martinussen, L. Christiansen et al., "Increased effect of the $A p o E$ gene on survival at advanced age in healthy and long-lived Danes: two nationwide cohort studies," Aging Cell, vol. 9, no. 6, pp. 1004-1009, 2010.

[30] M. Beekman, H. Blanché, M. Perola et al., "Genome-wide linkage analysis for human longevity: genetics of healthy aging study," Aging Cell, vol. 12, no. 2, pp. 184-193, 2013.

[31] E. Tedone, B. Arosio, C. Gussago et al., "Leukocyte telomere length and prevalence of age-related diseases in semisupercentenarians, centenarians and centenarians' offspring," Experimental Gerontology, vol. 58, pp. 90-95, 2014.

[32] J. T. Bell, P. C. Tsai, T. P. Yang et al., "Epigenome-wide scans identify differentially methylated regions for age and agerelated phenotypes in a healthy ageing population," PLoS Genetics, vol. 8, no. 4, article e1002629, 2012.

[33] K. Hirvonen, H. Laivuori, J. Lahti, T. Strandberg, J. G. Eriksson, and P. Hackman, "Sirt6 polymorphism Rs117385980 is associated with longevity and healthy aging in Finnish men," BMC Medical Genetics, vol. 18, no. 1, p. $41,2017$.

[34] Y. H. He, X. Lu, L. Q. Yang, L. Y. Xu, and Q. P. Kong, "Association of the insulin-like growth factor binding protein 3 (Igfbp-3) polymorphism with longevity in Chinese nonagenarians and centenarians," Aging, vol. 6, no. 11, pp. 944-951, 2014.

[35] B. Franzke, O. Neubauer, and K. H. Wagner, "Super DNAging-new insights into DNA integrity, genome stability and telomeres in the oldest old," Mutation Research/Reviews in Mutation Research, vol. 766, pp. 4857, 2015.

[36] J. A. Chesky, "The biology of aging: observations \& principles (3rd Edition) by Robert Arking," Educational Gerontology, vol. 33, no. 9, pp. 796-798, 2007.

[37] M. K. Rohr and F. R. Lang, "Aging well together - a minireview," Gerontology, vol. 55, no. 3, pp. 333-343, 2009.

[38] J. Vijg and Y. Suh, "Genome instability and aging," Annual Review of Physiology, vol. 75, no. 1, pp. 645-668, 2013.

[39] V. Humphreys, R. M. Martin, B. Ratcliffe et al., "Age-related increases in DNA repair and antioxidant protection: a comparison of the Boyd Orr cohort of elderly subjects with a younger population sample," Age and Ageing, vol. 36, no. 5, pp. 521-526, 2007. 
[40] M. Chevanne, C. Calia, M. Zampieri et al., "Oxidative DNA damage repair and Parp 1 and Parp 2 expression in Epstein-Barr virus-immortalized B lymphocyte cells from young subjects, old subjects, and centenarians," Rejuvenation Research, vol. 10, no. 2, pp. 191-204, 2007.

[41] N. Arantes-Oliveira, J. R. Berman, and C. Kenyon, "Healthy animals with extreme longevity," Science, vol. 302, no. 5645, pp. 611-611, 2003.

[42] L. Guarente and C. Kenyon, "Genetic pathways that regulate ageing in model organisms," Nature, vol. 408, no. 6809, pp. 255-262, 2000.

[43] I. M. Hadshiew, M. S. Eller, and B. A. Gilchrest, "Age-associated decreases in human DNA repair capacity: implications for the skin," Age, vol. 22, no. 2, pp. 45-57, 1999.

[44] J. Labat-Robert and L. Robert, "Longevity and aging. Mechanisms and perspectives," Pathologie Biologie, vol. 63, no. 6, pp. 272-276, 2015.

[45] M. L. Kern, S. S. Della Porta, and H. S. Friedman, "Lifelong pathways to longevity: personality, relationships, flourishing, and health," Journal of Personality, vol. 82, no. 6, pp. 472484, 2014.

[46] L. Salaris, "Differential mortality in a long-living community in Sardinia (Italy): a cohort analysis," Journal of Biosocial Science, vol. 47, no. 4, pp. 521-535, 2015.

[47] S. K. Keadle, H. Arem, S. C. Moore, J. N. Sampson, and C. E. Matthews, "Impact of changes in television viewing time and physical activity on longevity: a prospective cohort study," International Journal of Behavioral Nutrition and Physical Activity, vol. 12, no. 1, p. 156, 2015.

[48] J. Deelen, M. Beekman, M. Capri, C. Franceschi, and P. E. Slagboom, "Identifying the genomic determinants of aging and longevity in human population studies: progress and challenges," BioEssays, vol. 35, no. 4, pp. 386-396, 2013.

[49] P. E. Slagboom, M. Beekman, W. M. Passtoors et al., "Genomics of human longevity," Philosophical Transactions of the Royal Society B: Biological Sciences, vol. 366, no. 1561, pp. 35-42, 2011.

[50] S. C. Nolen, M. A. Evans, A. Fischer, M. M. Corrada, C. H. Kawas, and D. A. Bota, "Cancer-incidence, prevalence and mortality in the oldest-old. A comprehensive review," Mechanisms of Ageing and Development, vol. 164, pp. 113-126, 2017.

[51] N. Pavlidis, G. Stanta, and R. A. Audisio, "Cancer prevalence and mortality in centenarians: a systematic review," Critical Reviews in Oncology/Hematology, vol. 83, no. 1, pp. 145152, 2012.

[52] D. F. Terry, P. Sebastiani, S. L. Andersen, and T. T. Perls, "Disentangling the roles of disability and morbidity in survival to exceptional old age," Archives of Internal Medicine, vol. 168, no. 3, pp. 277-283, 2008.

[53] K. Christensen, M. McGue, I. Petersen, B. Jeune, and J. W. Vaupel, "Exceptional longevity does not result in excessive levels of disability," Proceedings of the National Academy of Sciences of the United States of America, vol. 105, no. 36, pp. 13274-13279, 2008.

[54] M. Chevanne, R. Caldini, D. Tombaccini, A. Mocali, G. Gori, and F. Paoletti, "Comparative levels of DNA breaks and sensitivity to oxidative stress in aged and senescent human fibroblasts: a distinctive pattern for centenarians," Biogerontology, vol. 4, no. 2, pp. 97-104, 2003.
[55] R. Arking, Biology of Aging: Observations and Principles, Oxford University Press, Oxford, UK, 2006.

[56] B. Liu, J. Wang, K. M. Chan et al., "Genomic instability in laminopathy-based premature aging," Nature Medicine, vol. 11, no. 7, pp. 780-785, 2005.

[57] S. Chang, A. S. Multani, N. G. Cabrera et al., "Essential role of limiting telomeres in the pathogenesis of Werner syndrome," Nature Genetics, vol. 36, no. 8, pp. 877-882, 2004.

[58] M. Yaar and B. A. Gilchrest, "Photoageing: mechanism, prevention and therapy," British Journal of Dermatology, vol. 157, no. 5, pp. 874-887, 2007.

[59] K. W. Caldecott, "Single-strand break repair and genetic disease," Nature Reviews Genetics, vol. 9, no. 8, pp. 619-631, 2008.

[60] G. M. Li, "Mechanisms and functions of DNA mismatch repair," Cell Research, vol. 18, no. 1, pp. 85-98, 2008.

[61] J. H. J. Hoeijmakers, "Genome maintenance mechanisms for preventing cancer," Nature, vol. 411, no. 6835, pp. 366-374, 2001.

[62] S. J. Haring, A. C. Mason, S. K. Binz, and M. S. Wold, "Cellular functions of human RPA1. Multiple roles of domains in replication, repair, and checkpoints," Journal of Biological Chemistry, vol. 283, no. 27, pp. 19095-19111, 2008.

[63] V. Gorbunova, A. Seluanov, Z. Mao, and C. Hine, "Changes in DNA repair during aging," Nucleic Acids Research, vol. 35, no. 22, pp. 7466-7474, 2007.

[64] M. L. Fishel, M. R. Vasko, and M. R. Kelley, "DNA repair in neurons: so if they don't divide what's to repair?," Mutation Research/Fundamental and Molecular Mechanisms of Mutagenesis, vol. 614, no. 1-2, pp. 24-36, 2007.

[65] T. Bessho, "Induction of DNA replication-mediated double strand breaks by psoralen DNA interstrand cross-links," Journal of Biological Chemistry, vol. 278, no. 7, pp. 52505254, 2003.

[66] S. C. West, "Molecular views of recombination proteins and their control," Nature Reviews Molecular Cell Biology, vol. 4, no. 6, pp. 435-445, 2003.

[67] M. R. Lieber, Y. Ma, U. Pannicke, and K. Schwarz, "Mechanism and regulation of human non-homologous DNA end-joining," Nature Reviews Molecular Cell Biology, vol. 4, no. 9, pp. 712-720, 2003.

[68] C. Garm, M. Moreno-Villanueva, A. Burkle et al., "Age and gender effects on DNA strand break repair in peripheral blood mononuclear cells," Aging Cell, vol. 12, no. 1, pp. 5866, 2013

[69] Z. Li, W. Zhang, Y. Chen et al., "Impaired DNA doublestrand break repair contributes to the age-associated rise of genomic instability in humans," Cell Death \& Differentiation, vol. 23, no. 11, pp. 1765-1777, 2016.

[70] V. Gorbunova and A. Seluanov, "DNA double strand break repair, aging and the chromatin connection," Mutation Research/Fundamental and Molecular Mechanisms of Mutagenesis, vol. 788, pp. 2-6, 2016.

[71] H. Li, J. R. Mitchell, and P. Hasty, "DNA double-strand breaks: a potential causative factor for mammalian aging?," Mechanisms of Ageing and Development, vol. 129, no. 7-8, pp. 416-424, 2008.

[72] Y. Li, L. Piao, K.-J. Yang et al., “Activation mechanism of protein kinase B by DNA-dependent protein kinase involved in the DNA repair system," Toxicological Research, vol. 24, no. 3, pp. 175-182, 2008. 
[73] M. Cirillo, O. Terradura-Vagnarelli, M. Mancini, A. Menotti, A. Zanchetti, and M. Laurenzi, "Cohort profile: the Gubbio population study," International Journal of Epidemiology, vol. 43, no. 3, pp. 713-720, 2014.

[74] L. Comai and B. Li, "The Werner syndrome protein at the crossroads of DNA repair and apoptosis," Mechanisms of Ageing and Development, vol. 125, no. 8, pp. 521-528, 2004.

[75] S. Espejel, M. Martin, P. Klatt, J. Martin-Caballero, J. M. Flores, and M. A. Blasco, "Shorter telomeres, accelerated ageing and increased lymphoma in DNA-PKcs-deficient mice," EMBO Reports, vol. 5, no. 5, pp. 503-509, 2004.

[76] H. Vogel, D. S. Lim, G. Karsenty, M. Finegold, and P. Hasty, "Deletion of Ku86 causes early onset of senescence in mice," Proceedings of the National Academy of Sciences of the United States of America, vol. 96, no. 19, pp. 10770-10775, 1999.

[77] M. Van Meter, M. Simon, G. Tombline et al., "JNK phosphorylates SIRT6 to stimulate DNA double-strand break repair in response to oxidative stress by recruiting PARP1 to DNA breaks," Cell Reports, vol. 16, no. 10, pp. 26412650, 2016.

[78] D. Harman, “Aging: overview," Annals of the New York Academy of Sciences, vol. 928, pp. 1-21, 2001.

[79] R. S. Balaban, S. Nemoto, and T. Finkel, "Mitochondria, oxidants, and aging," Cell, vol. 120, no. 4, pp. 483-495, 2005.

[80] E. Müllner, H. Brath, D. Toferer et al., "Genome damage in peripheral blood lymphocytes of diabetic and non-diabetic individuals after intervention with vegetables and plant oil," Mutagenesis, vol. 28, no. 2, pp. 205-211, 2013.

[81] A. A. Freitas and J. P. de Magalhaes, "A review and appraisal of the DNA damage theory of ageing," Mutation Research/ Reviews in Mutation Research, vol. 728, no. 1-2, pp. 12-22, 2011.

[82] S. Maynard, S. H. Schurman, C. Harboe, N. C. de SouzaPinto, and V. A. Bohr, "Base excision repair of oxidative DNA damage and association with cancer and aging," Carcinogenesis, vol. 30, no. 1, pp. 2-10, 2009.

[83] G. W. Intano, E. J. Cho, C. A. McMahan, and C. A. Walter, "Age-related base excision repair activity in mouse brain and liver nuclear extracts," The Journals of Gerontology Series A: Biological Sciences and Medical Sciences, vol. 58, no. 3, pp. B205-B211, 2003.

[84] J. M. J. Houben, E. J. Giltay, N. Rius-Ottenheim, G. J. Hageman, and D. Kromhout, "Telomere length and mortality in elderly men: the Zutphen Elderly Study," The Journals of Gerontology Series A: Biological Sciences and Medical Sciences, vol. 66A, no. 1, pp. 38-44, 2011.

[85] K.-I. Nakamura, K. Takubo, N. Izumiyama-Shimomura et al., "Telomeric DNA length in cerebral gray and white matter is associated with longevity in individuals aged 70 years or older," Experimental Gerontology, vol. 42, no. 10, pp. 944950, 2007.

[86] M. Kimura, M. Barbieri, J. P. Gardner et al., "Leukocytes of exceptionally old persons display ultra-short telomeres," American Journal of Physiology-Regulatory, Integrative and Comparative Physiology, vol. 293, no. 6, pp. R2210-R2217, 2007.

[87] M. Khaidakov, R. H. Heflich, M. G. Manjanatha, M. B. Myers, and A. Aidoo, "Accumulation of point mutations in mitochondrial DNA of aging mice," Mutation Research/Fundamental and Molecular Mechanisms of Mutagenesis, vol. 526, no. 1-2, pp. 1-7, 2003.
[88] U. Swain and K. Subba Rao, "Study of DNA damage via the comet assay and base excision repair activities in rat brain neurons and astrocytes during aging," Mechanisms of Ageing and Development, vol. 132, no. 8-9, pp. 374381, 2011.

[89] B. Szczesny and S. Mitra, "Effect of aging on intracellular distribution of abasic (AP) endonuclease 1 in the mouse liver," Mechanisms of Ageing and Development, vol. 126, no. 10, pp. 1071-1078, 2005.

[90] S. Madlener, T. Strobel, S. Vose et al., "Essential role for mammalian apurinic/apyrimidinic (AP) endonuclease Ape1/Ref-1 in telomere maintenance," Proceedings of the National Academy of Sciences of the United States of America, vol. 110, no. 44, pp. 17844-17849, 2013.

[91] J. S. Park, H. L. Kim, Y. J. Kim et al., "Human AP endonuclease 1: a potential marker for the prediction of environmental carcinogenesis risk," Oxidative Medicine and Cellular Longevity, vol. 2014, Article ID 730301, 15 pages, 2014.

[92] J.-O. Andressoo, J. H. J. Hoeijmakers, and J. R. Mitchell, "Nucleotide excision repair disorders and the balance between cancer and aging," Cell Cycle, vol. 5, no. 24, pp. 2886-2888, 2006.

[93] S. L. Yu and S. K. Lee, "Ultraviolet radiation: DNA damage, repair, and human disorders," Molecular \& Cellular Toxicology, vol. 13, no. 1, pp. 21-28, 2017.

[94] S. Moriwaki and Y. Takahashi, "Photoaging and DNA repair," Journal of Dermatological Science, vol. 50, no. 3, pp. 169-176, 2008.

[95] G. M. Martin and J. Oshima, "Lessons from human progeroid syndromes," Nature, vol. 408, no. 6809, pp. 263-266, 2000.

[96] P. Hasty, J. Campisi, J. Hoeijmakers, H. van Steeg, and J. Vijg, "Aging and genome maintenance: lessons from the mouse?," Science, vol. 299, no. 5611, pp. 1355-1359, 2003.

[97] J. P. de Magalhães and R. G. A. Faragher, "Cell divisions and mammalian aging: integrative biology insights from genes that regulate longevity," BioEssays, vol. 30, no. 6, pp. 567578, 2008.

[98] G. M. Martin, "Genetic modulation of senescent phenotypes in Homo sapiens," Cell, vol. 120, no. 4, pp. 523-532, 2005.

[99] B. P. Best, "Nuclear DNA damage as a direct cause of aging," Rejuvenation Research, vol. 12, no. 3, pp. 199-208, 2009.

[100] M. Yamada, M. U. Udono, M. Hori et al., "Aged human skin removes UVB-induced pyrimidine dimers from the epidermis more slowly than younger adult skin in vivo," Archives of Dermatological Research, vol. 297, no. 7, pp. 294-302, 2006.

[101] F. Hazane, S. Sauvaigo, T. Douki, A. Favier, and J. C. Beani, "Age-dependent DNA repair and cell cycle distribution of human skin fibroblasts in response to UVA irradiation," Journal of Photochemistry and Photobiology B: Biology, vol. 82, no. 3, pp. 214-223, 2006.

[102] T. J. Merkle, K. O’Brien, P. J. Brooks, R. E. Tarone, and J. H. Robbins, "DNA repair in human fibroblasts, as reflected by host-cell reactivation of a transfected UV-irradiated luciferase gene, is not related to donor age," Mutation Research/ Fundamental and Molecular Mechanisms of Mutagenesis, vol. 554, no. 1-2, pp. 9-17, 2004.

[103] D. Edifizi and B. Schumacher, "Genome instability in development and aging: insights from nucleotide excision repair in humans, mice, and worms," Biomolecules, vol. 5, no. 3, pp. 1855-1869, 2015. 
[104] B. Schumacher, "Transcription-blocking DNA damage in aging: a mechanism for hormesis," BioEssays, vol. 31, no. 12, pp. 1347-1356, 2009.

[105] R. J. Monnat Jr., "From broken to old: DNA damage, IGF1 endocrine suppression and aging," DNA Repair, vol. 6, no. 9, pp. 1386-1390, 2007.

[106] H. Lans, J. M. Lindvall, K. Thijssen et al., "DNA damage leads to progressive replicative decline but extends the life span of long-lived mutant animals," Cell Death \& Differentiation, vol. 20, no. 12, pp. 1709-1718, 2013.

[107] B. Schumacher, I. van der Pluijm, M. J. Moorhouse et al., "Delayed and accelerated aging share common longevity assurance mechanisms," PLoS Genetics, vol. 4, no. 8, article e1000161, 2008.

[108] M. van de Ven, J. O. Andressoo, V. B. Holcomb et al., "Extended longevity mechanisms in short-lived progeroid mice: identification of a preservative stress response associated with successful aging," Mechanisms of Ageing and Development, vol. 128, no. 1, pp. 58-63, 2007.

[109] R. L. Sprott, "Biomarkers of aging and disease: introduction and definitions," Experimental Gerontology, vol. 45, no. 1, pp. 2-4, 2010.

[110] M. Kuningas, K. Estrada, Y. H. Hsu et al., "Large common deletions associate with mortality at old age," Human Molecular Genetics, vol. 20, no. 21, pp. 4290-4296, 2011.

[111] H. T. Bae, P. Sebastiani, J. X. Sun et al., "Genome-wide association study of personality traits in the long life family study," Frontiers in Genetics, vol. 4, p. 65, 2013.

[112] D. Ben-Avraham, R. H. Muzumdar, and G. Atzmon, "Epigenetic genome-wide association methylation in aging and longevity," Epigenomics, vol. 4, no. 5, pp. 503-509, 2012.

[113] L. W. Harries, A. D. Fellows, L. C. Pilling et al., "Advancing age is associated with gene expression changes resembling mTOR inhibition: evidence from two human populations," Mechanisms of Ageing and Development, vol. 133, no. 8, pp. 556-562, 2012.

[114] J. K. Choi, "Next-generation genomics: an application to the study of epigenetic DNA repair mechanisms," Molecular \& Cellular Toxicology, vol. 6, no. 3, p. 30, 2010.

[115] M. Beekman, C. Nederstigt, H. E. D. Suchiman et al., "Genome-wide association study (GWAS)-identified disease risk alleles do not compromise human longevity," Proceedings of the National Academy of Sciences of the United States of America, vol. 107, no. 42, pp. 1804618049, 2010.

[116] E. M. Crimmins and C. E. Finch, "The genetics of age-related health outcomes," The Journals of Gerontology Series A: Biological Sciences and Medical Sciences, vol. 67A, no. 5, pp. 467-469, 2012.

[117] A. H. Shadyab and A. Z. LaCroix, "Genetic factors associated with longevity: a review of recent findings," Ageing Research Reviews, vol. 19, pp. 1-7, 2015.

[118] M. Soerensen, M. Nygaard, B. Debrabant et al., "No association between variation in longevity candidate genes and aging-related phenotypes in oldest-old danes," Experimental Gerontology, vol. 78, pp. 57-61, 2016.

[119] M. Soerensen, S. Dato, Q. Tan et al., "Human longevity and variation in GH/IGF-1/insulin signaling, DNA damage signaling and repair and pro/antioxidant pathway genes: cross sectional and longitudinal studies," Experimental Gerontology, vol. 47, no. 5, pp. 379-387, 2012.
[120] J. Deelen, H. W. Uh, R. Monajemi et al., "Gene set analysis of GWAS data for human longevity highlights the relevance of the insulin/IGF-1 signaling and telomere maintenance pathways," Age, vol. 35, no. 1, pp. 235-249, 2013.

[121] L. Broer and C. M. van Duijn, "GWAS and meta-analysis in aging/longevity," Advances in Experimental Medicine and Biology, vol. 847, pp. 107-125, 2015.

[122] J. P. de Magalhães, J. Costa, and O. Toussaint, "HAGR: the human ageing genomic resources," Nucleic Acids Research, vol. 33, no. Database issue, pp. D537-D543, 2005.

[123] J. P. de Magalhaes, A. Budovsky, G. Lehmann et al., "The human ageing genomic resources: online databases and tools for biogerontologists," Aging Cell, vol. 8, no. 1, pp. 65-72, 2009.

[124] R. Tacutu, T. Craig, A. Budovsky et al., "Human ageing genomic resources: integrated databases and tools for the biology and genetics of ageing," Nucleic Acids Research, vol. 41, pp. D1027-D1033, 2013.

[125] R. Tacutu, D. Thornton, E. Johnson et al., "Human ageing genomic resources: new and updated databases," Nucleic Acids Research, vol. 46, no. D1, pp. D1083-D1090, 2018.

[126] A. Budovsky, T. Craig, J. Wang et al., "Longevitymap: a database of human genetic variants associated with longevity," Trends in Genetics, vol. 29, no. 10, pp. 559-560, 2013.

[127] S. E. Bojesen and B. G. Nordestgaard, "The common germline Arg72pro polymorphism of P53 and increased longevity in humans," Cell Cycle, vol. 7, no. 2, pp. 158-163, 2008.

[128] F. Di Pietro, S. Dato, F. M. Carpi et al., “Tp53* P72 allele influences negatively female life expectancy in a population of Central Italy: cross-sectional study and geneticdemographic approach analysis," The Journals of Gerontology Series A: Biological Sciences and Medical Sciences, vol. 68, no. 5, pp. 539-545, 2013.

[129] A. Nikitin, S. Egorov, N. Daraselia, and I. Mazo, "Pathway Studio-the analysis and navigation of molecular networks," Bioinformatics, vol. 19, no. 16, pp. 2155-2157, 2003.

[130] S. L. MacRae, M. M. Croken, R. B. Calder et al., "DNA repair in species with extreme lifespan differences," Aging, vol. 7, no. 12, pp. 1171-1182, 2015.

[131] B. Schumacher, J. H. Hoeijmakers, and G. A. Garinis, "Sealing the gap between nuclear dna damage and longevity," Molecular and Cellular Endocrinology, vol. 299, no. 1, pp. 112-117, 2009.

[132] T. Chen, B. Dong, Z. Lu et al., "A functional single nucleotide polymorphism in promoter of ATM is associated with longevity," Mechanisms of Ageing and Development, vol. 131, no. 10, pp. 636-640, 2010.

[133] I. Piaceri, S. Bagnoli, A. Tedde, S. Sorbi, and B. Nacmias, "Ataxia-telangiectasia mutated (ATM) genetic variant in italian centenarians," Neurological Sciences, vol. 34, no. 4, pp. 573-575, 2013.

[134] A. I. Yashin, D. Wu, K. G. Arbeev, and S. V. Ukraintseva, "Polygenic effects of common single-nucleotide polymorphisms on life span: when association meets causality," Rejuvenation Research, vol. 15, no. 4, pp. 381-394, 2012.

[135] J. W. Park, Y. I. Ji, Y. H. Choi et al., "Candidate gene polymorphisms for diabetes mellitus, cardiovascular disease and cancer are associated with longevity in Koreans," Experimental \& Molecular Medicine, vol. 41, no. 11, pp. 772-781, 2009. 
[136] J. Polosak, M. Roszkowska-Gancarz, A. Kurylowicz et al., "Decreased expression and the Lys751Gln polymorphism of the XPD gene are associated with extreme longevity," Biogerontology, vol. 11, no. 3, pp. 287-297, 2010.

[137] A. Nebel, F. Flachsbart, A. Till et al., "A functional EXO1 promoter variant is associated with prolonged life expectancy in centenarians," Mechanisms of Ageing and Development, vol. 130, no. 10, pp. 691-699, 2009.

[138] K. Altomare, V. Greco, D. Bellizzi et al., "The allele (A) ${ }_{-110}$ in the promoter region of the HSP70-1 gene is unfavorable to longevity in women," Biogerontology, vol. 4, no. 4, pp. 215220, 2003.

[139] R. Singh, S. Kølvraa, P. Bross et al., “Association between low self-rated health and heterozygosity for $-110 \mathrm{a}>\mathrm{C}$ polymorphism in the promoter region of Hsp70-1 in aged Danish twins," Biogerontology, vol. 5, no. 3, pp. 169-176, 2004.

[140] R. Singh, S. Kolvraa, P. Bross et al., "Heat-shock protein 70 genes and human longevity: a view from Denmark," Annals of the New York Academy of Sciences, vol. 1067, no. 1, pp. 301-308, 2006.

[141] R. Singh, S. Kolvraa, P. Bross et al., "Anti-inflammatory heat shock protein 70 genes are positively associated with human survival," Current Pharmaceutical Design, vol. 16, no. 7, pp. 796-801, 2010.

[142] J. Li, W. Niu, Y. Qi et al., "Interactive association of heat shock protein 70 genes variants with natural longevity in Xinjiang Hetian Uygur ethnicity," Translational Research, vol. 154, no. 5, pp. 257-264, 2009.

[143] D. J. Kim, S. M. Yi, S. Y. Lee et al., "Association between the Mlh1 gene and longevity," Human Genetics, vol. 119, no. 3, pp. 353-354, 2006.

[144] L. Zhao, H. Hou, K. Iwasaki, A. Terada, and M. Hosomi, "Utilization of recycled charcoal as a thermal source and adsorbent for the treatment of Pcdd/Fs contaminated sediment," Journal of Hazardous Materials, vol. 225-226, pp. 182-189, 2012.

[145] S. Kim, X. Bi, M. Czarny-Ratajczak et al., “Telomere maintenance genes Sirt1 and Xrcc6 impact age-related decline in telomere length but only Sirt1 is associated with human longevity," Biogerontology, vol. 13, no. 2, pp. 119-131, 2012.

[146] S. M. Figarska, J. M. Vonk, and H. M. Boezen, "Sirt1 polymorphism, long-term survival and glucose tolerance in the general population," PLoS One, vol. 8, no. 3, article e58636, 2013. 


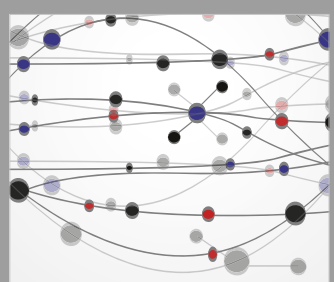

The Scientific World Journal
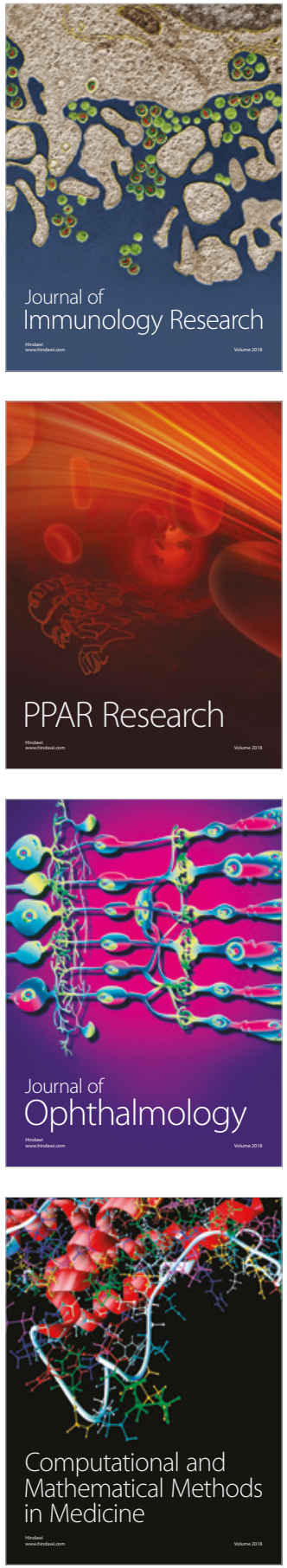

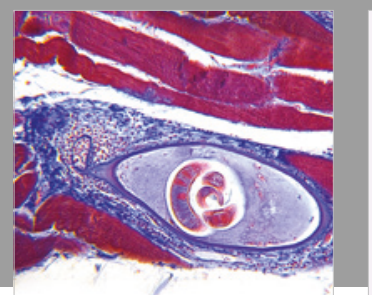

Gastroenterology Research and Practice

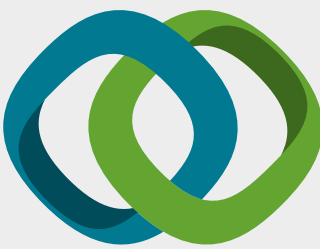

\section{Hindawi}

Submit your manuscripts at

www.hindawi.com
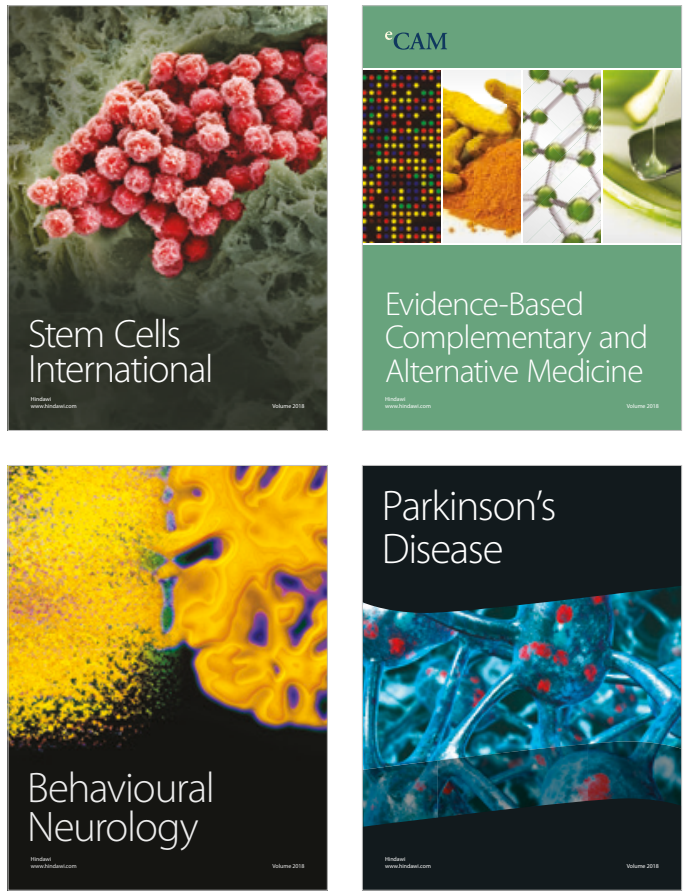

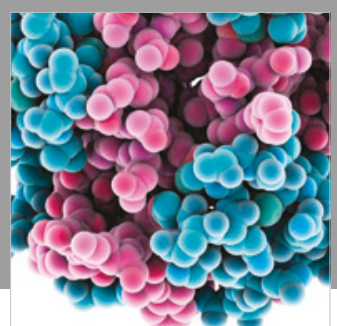

ournal of

Diabetes Research

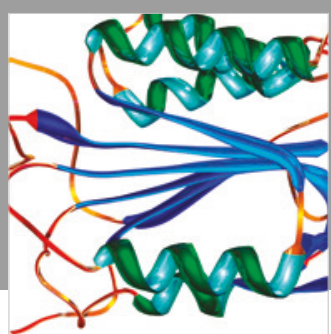

Disease Markers
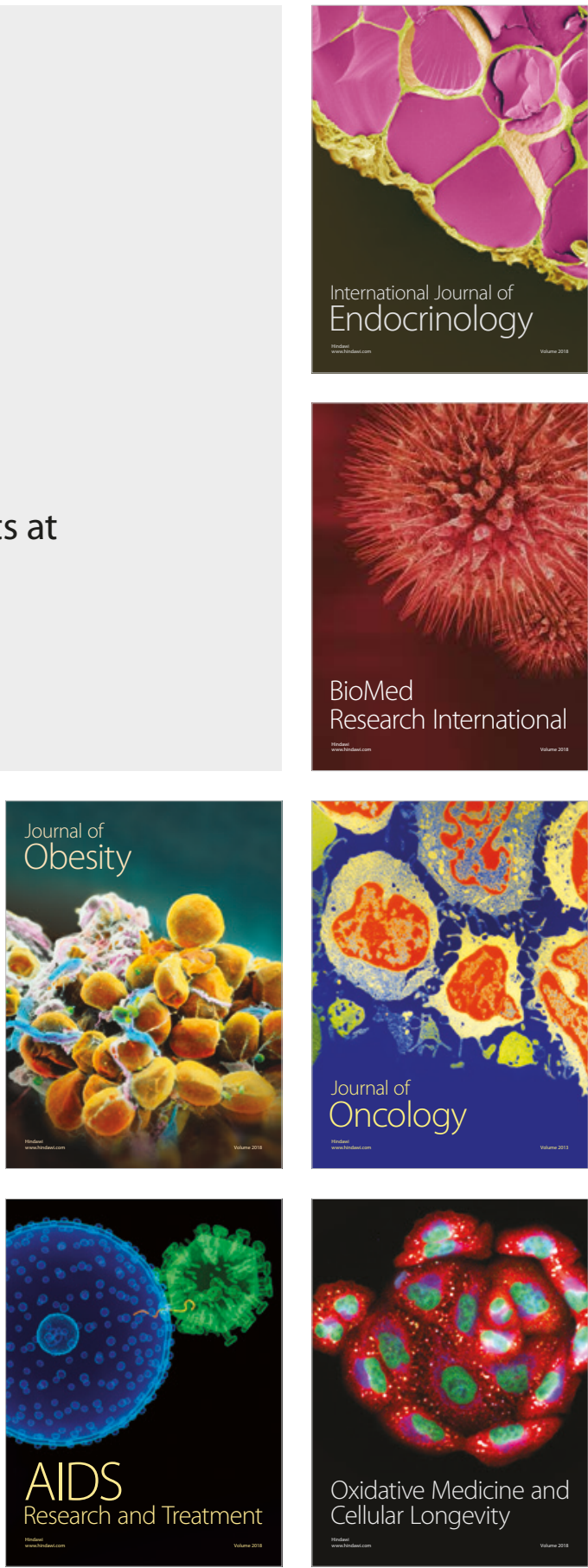